\title{
Organization in audition by similarity in rate of change: Evidence from tracking individual frequency glides in mixtures
}

\author{
LESLIE MAGGIE PERRIN MCPHERSON, VALTER CIOCCA, and ALBERT S. BREGMAN \\ McGill University, Montréal, Québec, Canada
}

\begin{abstract}
In audition, sound energy is assigned to separate auditory "streams" following principles of organization that closely parallel the visual gestalt principles that guide the perception of distinct forms or objects. Metzger (1934) provided evidence for organization in vision based on similarity in the velocity of moving forms. If two dots approach one another along one spatial dimension, they may appear to cross and continue beyond their meeting point if their velocities differ; otherwise, they usually appear to change direction abruptly and retrace their movements. If an analogous auditory principle exists, with rate of change in frequency substituted for velocity of movement, two frequency glides that sweep through the same frequency range in opposite directions should be able to perceptually cross if their rates of change differ; otherwise, they should usually appear to change direction and retrace the same frequency region. Four experiments provided data in support of this hypothesis, and the results were consistent across experiments with varying stimuli and methods of presentation. When properties of the stimuli favored organization according to a principle of frequency proximity, the effect of a principle of rate similarity was attenuated but still evident.
\end{abstract}

Bregman (1990) describes principles of organization for audition that closely parallel principles of organization in vision ("gestalt principles"). The parallel becomes apparent when one substitutes frequency and difference in frequency in audition for spatial location and spatial distance in vision. For example, in keeping with the visual principle of spatial proximity, items are more likely to be grouped together as one "form" when they are separated by relatively small distances. This principle corresponds to an auditory principle of frequency proximity; tones are more likely to be grouped together as one auditory "stream" when they differ little in frequency.

One of the visual principles of organization is continuity (see Koffka, 1935). If shown a cross or an X, a human observer tends to interpret the figure as two smooth lines that overlap in the middle. In other words, the observer traces the identity of a line through the crossing point, thereby maximizing the continuity of each line. Few observers spontaneously arrive at an alternative organization in which an $\mathrm{X}$ is interpreted as the juxtaposition of a V-shaped form and an upside-down V-shaped form, or

\footnotetext{
We would like to thank Dick Hermes for his comments on the design of Experiment 1 and his suggestion to use slower rates of change for subsequent experiments. We also thank Brian C. J. Moore and two anonymous reviewers for their many useful comments on an earlier version of the paper. Valter Ciocca is now at the University of Hong Kong. Correspondence should be addressed to L. M. P. McPherson, Department of Psychology, McGill University, Stewart Biological Sciences Building, 1205 Avenue Docteur Penfield, Montréal, Quebec, Canada H3A 1BI (e-mail: Impm@teal.csn.org).
}

-Accepted by previous editor, Charles W. Eriksen as the juxtaposition of these two shapes: $>$ and $<$. Such interpretations would require identity to be traced through a sharp angle, which is not in accordance with a principle of continuity. If a principle of continuity exists in audition, where frequency is the analogue of spatial location in vision, one might expect that whenever both an ascending and a descending frequency glide or series of tones sweep through the same frequency range at the same time, the identity of a frequency glide or a series of tones would be traced through the crossing point. Several studies, though, indicate that identity is instead traced back across the frequency region already traversed so that the glide segments or tones in the upper half of the frequency range are grouped together and those in the lower half are grouped together (e.g., Tougas \& Bregman, 1985; see also Deutsch, 1975, 1982, for similar findings with the scale illusion). This finding is in keeping with a principle of frequency proximity and does not provide evidence for a principle of continuity in audition.

Bregman and Dannenbring (1973) found that segregation by frequency proximity of steady-state tones into an upper and a lower stream was partially inhibited when small gliding segments were added to the ends of the steady states to "point" to the frequency of the next or previous steady state. They interpreted this result as an effect of a principle of continuity (or trajectory following), but, as Bregman (1990) points out, the gliding segments also brought the frequencies of the tones at their end points closer together. The results can be interpreted just as easily as an effect of frequency proximity.

Perhaps the failure to find effects of a principle of continuity in audition can be attributed to a difference be- 
tween the lines making up an $\mathrm{X}$ and tones that change in frequency over time. A line does not consist of a series of points presented over time and perceptually grouped together. All of the points that make up the line are present simultaneously. In contrast, an auditory stream consisting of a series of tones (or a frequency glide) is built up perceptually across time; the tones at different frequencies are not present simultaneously. If this difference is removed, visual organization can no longer be found to obey a principle of continuity. In studies of visual organization in which observers must track two dots moving horizontally through a common region of space, the identity of each dot is not traced through the meeting point of the two dots in the typical case, but is instead traced through an abrupt change in direction and back across the same region of space already traversed, so that the dots appear to "bounce" off one another (Bosinelli, Canestrari, \& Minguzzi, 1960; Metzger, 1934). This organization holds even when the dots are drawn on the sides of the feet of a toy biped (a person or other animal), viewed from the side, and the legs are made to cross one another as in walking. Whenever the feet cross, each dot appears to jump to the other foot so that the apparent paths of the dots never cross (Kanizsa, 1979).

When percepts must be built up over time, identity will be traced easily through a crossing point or meeting point only if such an organization obeys a principle of similarity. Available evidence suggests that this is true for both vision and audition. Metzger (1934) found that a dot would more easily appear to continue beyond the meeting point of two moving dots if by doing so the dot maintained a degree of brightness or size that differed from that of the other dot. Tougas and Bregman (1985) found that tones in simultaneously presented ascending and descending series would be more easily followed through their meeting point if the timbre of the tones differed for the two series. By analogy with Metzger's brightness condition, the same result might be obtained with a marked difference in loudness between ascending and descending series of tones.

Metzger (1934) also found that the relative velocity of two moving dots played a role in their tracking. With two dots approaching one another at different velocities, a moving dot was often tracked through the meeting point so that its apparent velocity was maintained. The alternative organization, in which the dot appeared to change direction abruptly and move back over the same region of space (i.e., to bounce off the other dot), was sometimes observed as well, indicating that the facilitation of the perception of crossing dots was not accompanied by a strong inhibition of the perception of bouncing dots. If the correspondence between visual and auditory principles of organization holds, and if rate of change in frequency is the correct auditory analogue to velocity of movement in vision, then Metzger's finding suggests the following hypothesis: Given an ascending and a descending frequency glide that traverse the same frequency range at the same time, tracking of each frequency glide through the crossing point will be facilitated when the rate of change in frequency differs for the two glides. Four experiments were conducted to test this hypothesis. A description of those experiments and their results follows.

\section{GENERAL METHOD}

\section{Subjects}

Graduate students and technicians in psychology served as subjects. They were paid for their participation. All subjects had sensory thresholds in the normal range for frequencies between 250 and $4000 \mathrm{~Hz}$. The numbers of subjects in Experiments 1, 2, 3, and 4 were $11,11,12$, and 12 , respectively.

\section{Stimuli}

The stimuli consisted of combinations of exponential frequency glides (which change linearly in perceived pitch; see von Békésy, 1960). The stimuli used in Experiments 1 and 2 consisted of two tones that alternately rose and fell in frequency, "pausing" at the extremes of frequency (i.e., changing from glides to steady-state tones). The stimuli used in Experiments 3 and 4 were series of glides separated by silent intervals. At equally spaced intervals within each stimulus pattern, an ascending glide and a descending glide traveled in opposite directions through the same frequency range at the same time, crossing one another at or near the midpoint of their durations. The frequency range and timing of glides are described in later sections. In half of the stimulus patterns, the glides that crossed differed in rate of change in frequency. For the remaining patterns, the crossing glides had the same rate of change.

The stimulus patterns were imperfect analogues of the visual stimuli used by Metzger (1934). Metzger's pairs of moving dots followed perfectly sinusoidal paths, with one path $180^{\circ}$ out of phase with the second path so that the dots crossed in the center of their range of movement. A sinusoidal path of movement is associated with changes in velocity, with slower movement toward the extremes of the range of movement. The auditory stimuli we used contained glides that maintained a constant rate of change for their entire duration. Our stimuli differed from Metzger's in another way. In his displays, the dot that traveled faster also traveled through a greater distance (i.e., the sinusoid describing its path had a greater amplitude). In Experiment 4 of the present study, glides with a faster rate of change traveled through a greater frequency range, but in Experiments 1 to 3, all the glides traveled through the same frequency range.

The effect of similarity or dissimilarity in rate on streaming (i.e., the segregation of incoming sound to form separate auditory "objects" or "forms"; see Bregman, 1990) was ascertained by having subjects compare the streams of sound they perceived with "standard" patterns of sound presented separately. Because the stimulus patterns were compared with standards, the stimulus patterns will be called comparison patterns. Four standard patterns were created for each comparison pattern by extracting some subset of tone segments from the comparison pattern. One standard pattern consisted of the top half of a comparison pattern (the upper bouncing pattern), one consisted of the bottom half of the pattern (the lower bouncing pattern), one consisted of the tone (Experiments 1 and 2) or series of glides (Experiments 3 and 4) that began with an ascending glide, and one consisted of the initially descending tone or series of glides; these last two patterns (the crossing patterns) would match the streams that subjects perceived if they tracked the glides through their crossing point.

In addition to the experimental stimuli, practice stimuli were created. There were two comparison patterns for the practice trials. Each consisted of two crossing series of exponential glides. Descriptions of these stimuli appear in later sections of the paper. 


\section{Procedure}

A practice session began with two sets of eight trials. In the first set, which served as a warm-up to the more difficult second set, the subject heard a warning tone, 1 sec of silence, and then two sound patterns, one after the other and separated by $1 \mathrm{sec}$ of silence. The patterns were from the set of standard patterns (i.e., the two bouncing patterns and the two crossing patterns) for the comparison patterns used in the second set of practice trials. The two series of glides were identical on half of the trials and different on the other half. The subject was asked to judge whether the second series was the same as or different from the first. Decisions ("same" or "different") were registered with a keypress on a computer keyboard. Order of presentation was randomized separately for each subject.

The second set of practice trials also began with a warning tone followed by $1 \mathrm{sec}$ of silence. The subject was then presented with one of the four standard patterns, followed $1 \mathrm{sec}$ later by one of the two comparison patterns (which contained two crossing series of glides played simultaneously). The standard pattern was present in the comparison pattern on half of the trials. The subject was asked to judge whether either of the auditory streams perceived while listening to the mixture (i.e., the comparison pattern) sounded the same as the standard pattern and to register the decision with a keypress. If a subject failed to recognize the standard in the mixture when it was present or indicated that an absent standard was present on more than two trials, the practice trials were repeated until two or fewer such errors occurred in a set of trials. Most subjects required just one or two repetitions of the practice trials. Order of presentation was randomized separately for each set of practice trials and for each subject.

During the actual experiment, the sequence of presentation for each trial was as follows: a $100-\mathrm{msec} 1500-\mathrm{Hz}$ warning tone (played at $60 \mathrm{~dB}$ SPL), a 1-sec silence, one of the standard patterns, a 1sec silence, and then one of the comparison patterns. Each comparison pattern was paired, on four separate trials, with each of its four associated standards: the upper bouncing standard, the lower bouncing standard, and the two crossing standards. The order of trials was randomized separately for each subject. The subjects were constrained to respond within a 5-sec period of silence that followed presentation of the comparison pattern. Their response initiated the next trial.

The subjects responded on each trial by choosing a number on an 8-point confidence-rating scale. A value between 1 and 4 regstered a decision that the standard was absent from the mixture, and a value between 5 and 8 indicated that the standard was present. Numbers at the extreme ends of the scale represented a high level of confidence in the decision about the standard's presence or absence. Numbers at the middle of the scale represented lower levels of confidence. As part of the instructions for the task, the subjects were informed that the standard was present in the comparison pattern on a proportion of trials chosen randomly by the computer. In reality, the physical sounds making up the standard were always present in the comparison mixture, but perceptual processes did not always allocate these sounds to the same auditory stream, and so subjects often could not perceptually isolate the standard in the mixnure.

\section{Apparatus}

The glides were digitally synthesized using the MITSYN software package (see Henke, 1987) on a Compaq 386/20 computer controlling a Data Translation DT2823 16-bit D/A converter. The stimuli had a sampling rate of $16 \mathrm{kHz}$ and were lowpass filtered at $8 \mathrm{kHz}$ by a TTE J1550 filter, which provided an attenuation of $60 \mathrm{~dB}$ at $11.2 \mathrm{kHz}$. Since there was no energy above $4 \mathrm{kHz}$ in the synthesized stimuli prior to filtering, this filter effectively removed noise due to aliasing from the output signal. The subjects listened individually to the stimuli over Sony MDR-V7 headphones while seated alone in an Industrial Acoustics 1202 audiometric chamber.
Stimulus intensities were measured with a General Radio Type 1551$\mathrm{C}$ sound-level meter using the A weighting function; the meter was connected to the headphones with a flat-plate coupler. Subjects' hearing was tested using a Maico Hearing Instruments MA27 audiometer. The Compaq 386/20 computer recorded all responses, which were made by keypresses on a standard keyboard.

\section{Data Analysis}

For each comparison pattern, a measure of the tendency for the perceived streams of sound to bounce or cross was computed by summing the response values for the two bouncing standards and subtracting the sum of the responses for the two crossing standards. This measure can range in value from -14 to 14 , with positive scores indicating a greater tendency for the streams to bounce than to cross.

For each experiment, values on this measure were entered into an analysis of variance (ANOVA) as dependent measures. The rates of the two glides that crossed (fast or slow rate of change) were within-subjects factors in the design. If similarity in rate of change is related to the tendency of streams to bounce or cross, then an ANOVA should yield a significant interaction of the two rate factors due to lower values of the bouncing-crossing measure for the two comparison patterns in which the crossing glides differed in rate.

\section{EXPERIMENT 1}

\section{Method}

Stimuli. The stimuli are shown in Figure 1. Each can be described as two series of crossing exponential frequency glides, with the glides in each series joined at their ends by steady-state tones.

The exponential glides traveled from a frequency of 1000 to $2000 \mathrm{~Hz}$, or vice versa. Glides met at the midpoints of their durations at $1414.2 \mathrm{~Hz}$. Two rates were used; glides with the faster rate traversed the $1000-\mathrm{Hz}$ range in $100 \mathrm{msec}$ (for a rate of $10 \mathrm{oc}-$ taves/sec), and the slower glides traversed the same range in $400 \mathrm{msec}$ (for a rate of 2.5 octaves/sec). When glides with different rates were combined, a glide of a given rate began at the frequency where the last glide with that rate ended. Glides in the initially ascending series had the faster rate for half of the patterns and the slower rate for the other half, as did glides in the initially descending series, resulting in the four comparison patterns shown in Figure 1.

COMBINATIONS OF GLIDES WITH THE SAME RATE OF CHANGE

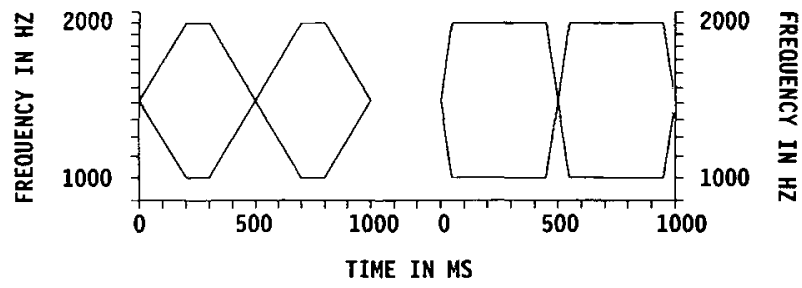
COMBINATIONS OF GLIDES WITH DIFFERENT RATES OF CHANGE

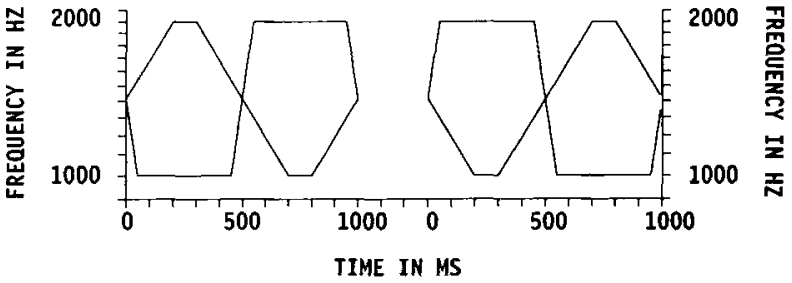

Figure 1. The four comparison patterns used in Experiment 1. 
Two sets of comparison patterns were presented. For one set, the steady-state tones connecting the fast glides at their ends had a duration of $400 \mathrm{msec}$ and those connecting the slow glides lasted $100 \mathrm{msec}$. For the other set, the steady states were $500 \mathrm{msec}$ longer so that the fast glides were connected by 900 -msec steady states and the slow glides were connected by 600 -msec steady states. The length of the steady-state tones was manipulated in this way as one means of gauging any possible effect of the steady states on perceptual organization, which might reveal itself in a comparison of steady states of different length. For the stimuli with relatively short steady states, the patterns shown in Figure 1 were repeated four times (with no intervening pauses); for the stimuli with longer steady states, the patterns shown in the figure were repeated twice. Each comparison pattern took $4 \mathrm{sec}$ to play. Rise times and decay times of $30 \mathrm{msec}$ were included to prevent onset and offset clicks.

All patterns were presented at a level of $60 \mathrm{~dB}$ SPL. According to equal-loudness contours, loudness should be fairly constant in the frequency range occupied by the glides (see Robinson \& Dadson, 1956).

The four standard patterns for one of the comparison patterns are shown in Figure 2.

There were two comparison patterns for the practice trials. In one comparison pattern, the glides traveled from 1150 to $1750 \mathrm{~Hz}$, or vice versa, in $600 \mathrm{msec}$. The glides crossed after $300 \mathrm{msec}$ at $1418.6 \mathrm{~Hz}$. There was no silence or steady-state tone separating the glides in the series. This pattern was chosen because the experimenters found it to be most readily organized on the basis of frequency proximity - that is, as upper and lower bouncing streamsand so it could provide subjects with practice in hearing bouncing. The standard patterns for this comparison pattern consisted of the top and bottom halves of the pattern. The second comparison pattern consisted of two crossing series of glides that met at $1418.6 \mathrm{~Hz}$ and that traversed their full frequency range every $600 \mathrm{msec}$ as before, but the glides in the two series differed in the range traversed (between 1150 and $1750 \mathrm{~Hz}$, or between 1400 and $1500 \mathrm{~Hz}$ ). The glides that traversed the smaller range changed frequency more slowly. Glides were always joined at their ends to subsequent glides of the same rate. This pattern was chosen because the experimenters found it to be most readily organized into two crossing streams, THE LAST PATTERN IN FIGURE 1
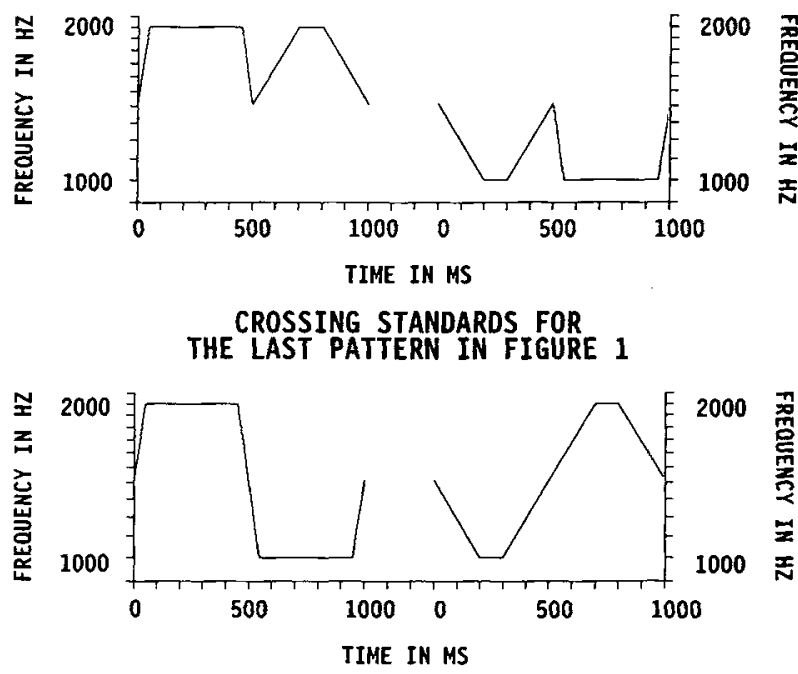

Figure 2. The four standard patterns for the last comparison pattern in Figure 1. and so it could provide subjects with practice in hearing crossing. The standard patterns for this comparison pattern consisted of the series of glides with the slower rate and the series with the faster rate; these correspond to the streams one would perceive if the comparison pattern was decomposed into two crossing glide series. Each of the four standards (two bouncing standards for the bouncing comparison, and two crossing standards for the crossing comparison) was paired with each comparison pattern on a separate trial so that the standard was present in the mixture on half of the eight trials.

Procedure. Each standard-comparison combination was presented twice, once in each of two blocks of trials. The order of trials was randomized separately for each block (and for each subject).

\section{Results}

The bouncing-crossing score was the dependent measure in an ANOVA with the following within-subjects independent measures: block of trials (first or second), length of steady-state tones (long or short), and, for the comparison patterns, rate (fast or slow) of glides in the series that began with a glide rising in frequency (initially ascending series) and rate (fast or slow) of glides in the series that began with a glide falling in frequency (initially descending series). Only main effects and interactions significant at the $\alpha=.01$ level will be discussed.

No effects involving the block-of-trials factor were significant. Two effects were significant. The first was the interaction consistent with the hypothesis-namely, the two-way interaction of the rate of glides in the initially ascending series with the rate of glides in the initially descending series $[F(1,10)=10.19, p<.01]$. The mean values of the bouncing-crossing measure were lower for the two comparison patterns in which the rates of the glides differed ( $M=6.50$ when the rates differed; $M=10.24$ when the rates were the same).

The second significant effect was the three-way interaction of the length of the steady-state tones with the two rates of glides $[F(1,10)=18.01, p<.01]$. With long steady-state tones, the interaction of the two rates was absent, with a dominance of bouncing in all conditions. The means for the four combinations of rates with short and long steady states are presented in Table 1 . Note that all of the values are positive, indicating a relative dominance of bouncing over crossing.

In order to assess the effects of practice at the task, the confidence ratings for each trial were correlated with the trial's place in the order of presentation (which varied from subject to subject). A positive correlation would indicate an increase across trials in the ability to detect a pattern matching the standard in the comparison mixture. (Remember that this pattern was always present.) None of the 64 correlations was significant at $\alpha=.01$. From these results and from the negative results for the block of trials factor in the ANOVA, one can conclude that practice did not facilitate the identification in the comparison mixture of a pattern matching the standard.

\section{Discussion}

The results of Experiment 1 suggest that the identity of a glide is more frequently traced through the meeting 
Table 1

Mean Differences Between Confidence Ratings for Bouncing Standards and Crossing Standards in Experiment 1

\begin{tabular}{|c|c|c|c|c|c|}
\hline \multirow{2}{*}{$\begin{array}{l}\text { Length of } \\
\text { Steady-State } \\
\text { Tones }\end{array}$} & \multicolumn{2}{|c|}{ Glide Rates } & \multicolumn{3}{|c|}{ Confidence Ratings* } \\
\hline & $\begin{array}{c}\text { Initially } \\
\text { Ascending }\end{array}$ & $\begin{array}{c}\text { Initially } \\
\text { Descending }\end{array}$ & $\begin{array}{c}\text { Mean } \\
\text { Differences }\end{array}$ & Rate(s) & Averages \\
\hline \multirow[t]{2}{*}{ Short } & $\begin{array}{l}\text { Slow } \\
\text { Fast }\end{array}$ & $\begin{array}{l}\text { Slow } \\
\text { Fast }\end{array}$ & $\begin{array}{l}10.86 \\
11.64\end{array}$ & Same & 11.25 \\
\hline & $\begin{array}{l}\text { Slow } \\
\text { Fast }\end{array}$ & $\begin{array}{l}\text { Fast } \\
\text { Slow }\end{array}$ & $\begin{array}{l}4.86 \\
5.14\end{array}$ & Different & 5.00 \\
\hline \multirow[t]{2}{*}{ Long } & $\begin{array}{l}\text { Slow } \\
\text { Fast }\end{array}$ & $\begin{array}{l}\text { Slow } \\
\text { Fast }\end{array}$ & $\begin{array}{r}7.82 \\
10.64\end{array}$ & Same & 9.23 \\
\hline & $\begin{array}{l}\text { Slow } \\
\text { Fast }\end{array}$ & $\begin{array}{l}\text { Fast } \\
\text { Slow }\end{array}$ & $\begin{array}{l}7.86 \\
8.14\end{array}$ & Different & 8.00 \\
\hline
\end{tabular}

*See Data Analysis in General Method section.

point of two glides when the glides differ in rate, presumably because of the operation of a principle of similarity. In spite of this increased tendency to hear the streams cross, the perception of bouncing streams was much more common; none of the mean differences between bouncing and crossing scores was below zero. For the stimuli used in Experiment 1, a principle of frequency proximity appears to dominate in the segregation of the sounds into separate streams. When glides were connected by long steady-state tones at the extremes of the frequency range, bouncing was so dominant that crossing streams were rarely perceived even when the rates of the glides differed.

The effect of the manipulation of rate cannot be attributed unequivocally to a difference in rate; when the rates differed, the series of glides differed not only in the rate of the glides but also in the length of the steady-state tones connecting the glides. Two crossing glides were constrained to meet in the middle of their durations, so the faster glide departed from one extreme of the frequency range later and arrived at the other extreme sooner than the slower glide, so that the "pauses" at the extremes (i.e., the steady-state tones) were longer for the faster glides. When the rates differed, the subjects need not have computed the rates for the two glides and compared their values. Instead, they might have adopted a strategy of ignoring the glides altogether and following the longer steady-state tones or the shorter ones (depending on the standard just played). In other words, the subjects might have been able to detect in a comparison pattern the tones making up one of its crossing standards by attending to the steady-state tones alone. Experiments 2 and 3 were designed to examine this possibility. In one condition of Experiment 2, the crossing point of the two glides was removed, preventing any computation or comparison of rate at that point. In Experiment 3, the glides were not connected by steady-state tones.

\section{EXPERIMENT 2}

\section{Method}

Stimuli. The comparison patterns and standard patterns were similar to those used in Experiment 1. As before, the exponential glides traveled from 1000 to $2000 \mathrm{~Hz}$, or vice versa, meeting at the midpoints in their durations at $1414.2 \mathrm{~Hz}$. In Experiment 2, the glides traversed the entire frequency range in either 200 or $800 \mathrm{msec}$, producing two rates ( 5 and 1.25 octaves/sec). These rates are slower than those of the glides in Experiment 1. There is evidence that (in the $1000-2000-\mathrm{Hz}$ range) faster glide rates sometimes make glides difficult to follow, or at least hinder discrimination of glide rates (e.g., Collins, 1984; for related evidence about formant transitions, see Porter, Cullen, Collins, \& Jackson, 1991); in so doing, they may favor grouping by frequency proximity.

The faster $(200$-msec) glides in this experiment were connected by 800 -msec steady-state tones, and the slower $(800-\mathrm{msec})$ ones were connected by 200 -msec steady states. Each comparison pattern consisted of two repetitions of a pattern similar in shape to one of the patterns in Figure 1. The complete comparison pattern took $4 \mathrm{sec}$ to play. For half of the trials, the $50-\mathrm{msec}$ portions of the glide preceding and following the crossing point were replaced with silent gaps so that the glides were interrupted by a 100 -msec gap at the crossing point. Wherever a glide began or ended, the rise time or decay time was $20 \mathrm{msec}$.

The practice stimuli were similar to those used in Experiment 1. The comparison pattern designed to give subjects practice in hearing bouncing consisted of two crossing series of exponential glides. The glides traversed a range of $600 \mathrm{~Hz}$ (between 1150 and $1750 \mathrm{~Hz}$ ) in $1,200 \mathrm{msec}$, meeting after $600 \mathrm{msec}$ at $1418.6 \mathrm{~Hz}$; there was no silence or steady-state tone separating glides. The standard patterns for this comparison pattern consisted of the top and bottom halves of the pattern. The comparison pattern designed to give subjects practice in hearing crossing streams consisted of two crossing series of glides, with the glides traversing their full frequency range in $1,200 \mathrm{msec}$ and crossing after $600 \mathrm{msec}$ as before, but glides in the two series differed in the range traversed: in one series, the glides traveled from 1150 to $1950 \mathrm{~Hz}$, or vice versa; in the other series, they traveled between 1250 and $1450 \mathrm{~Hz}$. Glides were always joined at their ends to subsequent glides of the same rate. The two standard patterns for this comparison pattern consisted of the series of glides with the slower rate and the series with the faster rate; these are the two patterns that would be heard as components if the glides crossed perceptually. For half of the 16 practice trials, the crossing points in the patterns were replaced with 100-msec silent gaps.

Procedure. The procedure was identical to that of Experiment 1. The trials were presented in two blocks; the complete patterns were presented in one block, and the patterns with silent gaps at the crossing points were presented in another block. Each block began with two sets of practice trials as before, using patterns that matched the experimental patterns in terms of the presence or absence of silent gaps. Six subjects heard the complete patterns in the first block 
and the patterns with gaps in the second block, and 5 subjects heard the patterns with gaps first and the complete patterns second.

\section{Results}

The bouncing-crossing score was the dependent measure in an ANOVA with order of blocks as a betweensubjects independent measure and with the following within-subjects independent measures: silent gap in glides (present or absent), and, for the comparison patterns, rate (fast or slow) of glides in the initially ascending series and rate (fast or slow) of glides in the initially descending series. No effects involving the order of the blocks of trials were significant. There were also no significant effects involving the presence or absence of a silent gap at the crossing point of the glides.

The main effect of the rate of the initially ascending series was significant $[F(1,9)=15.31, p<.01]$, with a higher mean when this rate was fast $(M=8.88$ for the fast rate; $M=6.53$ for the slow rate).

The interaction of the two rates of the glides was significant $[F(1,9)=14.69, p<.01]$. The mean score was significantly higher when the two glides had the same rate of change than when the rates differed, but this difference was due primarily to a high mean when both glides had the fast rate of change; when both rates were slow, the mean did not differ from the means for patterns combining glides of different rates according to post hoc tests (Tukey's honestly significant difference $[H S D]$ tests).

The means are shown in Table 2. As in Experiment 1, the bouncing-crossing means are all positive, indicating a relative dominance of perceived bouncing.

As in Experiment 1, there was no effect of practice as gauged by correlations between the confidence ratings for each trial and the trial's place in the order of presentation. None of the 32 correlations was significant at $\alpha=.01$.

\section{Discussion}

The results of Experiment 2 replicated the results of Experiment 1. As in Experiment 1, bouncing-crossing scores were lower when the rates of the glides in the two series differed than when they matched. The mean scores were all positive, indicating that bouncing was more readily perceived than crossing. The responses of subjects in Experiments 1 and 2 may reflect a mixture of organizational processes, with some effect of a streaming process based on similarity of rate, but with a larger effect of a streaming process based on frequency proximity. The large portions of the patterns at the highest and lowest frequencies (i.e., the steady states) might favor grouping according to upper and lower frequency regions so that bouncing is easy to perceive even when the glide rates differ.

The replacement of the crossing point with a silent gap did not eliminate the effect on perceived crossing of a difference in rate. This finding is consistent with the hypothesis that subjects could perceive crossing more easily when the rates of glides differed because they could follow steady states of the same length. Alternatively, the portions of the glides remaining on either side of the silent gap may have been of sufficient length for the rate of change to be computed and compared with the glide segments that followed. Neither of these explanations can be favored on the basis of this experiment alone. It was decided to run another experiment in which glides were not connected by steady-state tones.

In Experiment 3, the steady-state tones were removed from the comparison patterns in an attempt to more clearly reveal the effect of any streaming process sensitive to differences in rate of frequency change. In addition, Experiment 3 included a condition in which the standard pattern, rather than being presented before the comparison, was presented after three repetitions of the comparison pattern. This variation in the procedure was introduced to see whether the presentation of the standard prior to the comparison mixture in Experiments 1 and 2 had been creating a perceptual organization that differed from the "natural" one by encouraging subjects to search for the standard in the mixture.

\section{EXPERIMENT 3}

\section{Method}

Stimuli. The comparison patterns were similar to those used in Experiments 1 and 2, except that glides were not joined by steadystate tones. The exponential glides traversed the region between

Table 2

Mean Differences Between Confidence Ratings for Bouncing Standards and Crossing Standards in Experiment 2

\begin{tabular}{|c|c|c|c|c|c|}
\hline \multirow[b]{2}{*}{ Condition } & \multicolumn{2}{|c|}{ Glide Rates } & \multicolumn{3}{|c|}{ Confidence Ratings* } \\
\hline & $\begin{array}{c}\text { Initially } \\
\text { Ascending }\end{array}$ & $\begin{array}{c}\text { Initially } \\
\text { Descending }\end{array}$ & $\begin{array}{c}\text { Mean } \\
\text { Differences }\end{array}$ & Rate(s) & Averages \\
\hline \multirow[t]{2}{*}{ No Gap } & $\begin{array}{l}\text { Slow } \\
\text { Fast }\end{array}$ & $\begin{array}{l}\text { Slow } \\
\text { Fast }\end{array}$ & $\begin{array}{r}7.27 \\
10.98\end{array}$ & Same & 9.13 \\
\hline & $\begin{array}{l}\text { Slow } \\
\text { Fast }\end{array}$ & $\begin{array}{l}\text { Fast } \\
\text { Slow }\end{array}$ & $\begin{array}{l}5.33 \\
6.48\end{array}$ & Different & 5.91 \\
\hline \multirow[t]{2}{*}{ Gap } & $\begin{array}{l}\text { Slow } \\
\text { Fast }\end{array}$ & $\begin{array}{l}\text { Slow } \\
\text { Fast }\end{array}$ & $\begin{array}{r}6.52 \\
11.10\end{array}$ & Same & 8.81 \\
\hline & $\begin{array}{l}\text { Slow } \\
\text { Fast }\end{array}$ & $\begin{array}{l}\text { Fast } \\
\text { Slow }\end{array}$ & $\begin{array}{l}6.98 \\
6.95\end{array}$ & Different & 6.97 \\
\hline
\end{tabular}

*See Data Analysis in General Method section. 
1000 and $2000 \mathrm{~Hz}$, meeting at $1414.2 \mathrm{~Hz}$ at the midpoints in their durations. Glides swept through the entire range in either 200 or $800 \mathrm{msec}$ as in Experiment 2. The 200-msec glides were separated at their ends by 800 -msec silent gaps; the 800 -msec glides were separated by 200 -msec silent gaps. Wherever a glide began or ended, the rise time or decay time was $20 \mathrm{msec}$. (Each glide was preceded and followed by a 20 -msec steady-state tone to allow for rise and decay.) All possible combinations of the two rates produced four comparison patterns: two with crossing series of glides with the same rate, and two with crossing series of glides with different rates. An entire pattern took $3,800 \mathrm{msec}$ to play if it contained slower glides, or 3,200 msec if it contained only fast glides. One of the comparison patterns and its four standard patterns are shown in Figure 3 .

The practice stimuli were similar to those used in Experiment 2 except that glides were not joined at their ends. The comparison pattern designed to give subjects practice in hearing bouncing consisted of two crossing series of glides. The glides traversed a range of $600 \mathrm{~Hz}$ (between 1150 and $1750 \mathrm{~Hz}$ ) in $1,200 \mathrm{msec}$, meeting after $600 \mathrm{msec}$ at $1418.6 \mathrm{~Hz}$; there was a $300-\mathrm{msec}$ silence separating the glides. The standard patterns for this comparison pattern consisted of the top and bottom halves of the pattern. The comparison pattern designed to give subjects practice in hearing crossing streams consisted of two crossing series of glides as before, but the glides in the two series differed in the range traversed in $1,200 \mathrm{msec}$ (between 1150 and $1950 \mathrm{~Hz}$, or between 1250 and $1450 \mathrm{~Hz}$ ). Glides were always separated at their ends from subsequent glides of the same rate by a 300 -msec silent gap. The standard patterns for this comparison pattern consisted of the series of glides with the slower rate and the series with the faster rate; these are the two patterns that would be the components of the glide pattern if it was decomposed into crossing glides.

Procedure. The procedure was identical to that of Experiments 1 and 2 for one condition, but a second condition was added in which the comparison pattern was presented three times (with 1-sec silences between presentations) prior to presentation of the standard (which was presented once). The subjects thus had to organize the comparison mixture into separate streams of sound before they knew the nature of the pattern they would be asked to identify as present or absent. The trials were presented in two blocks; the mode of presentation (standard first or comparison first) was the same for all trials in a block. Each block began with two sets of practice trials as before, with the same mode of presentation for the practice trials as for the experimental trials. Six subjects heard the comparison pattern before the standard pattern in the first block and
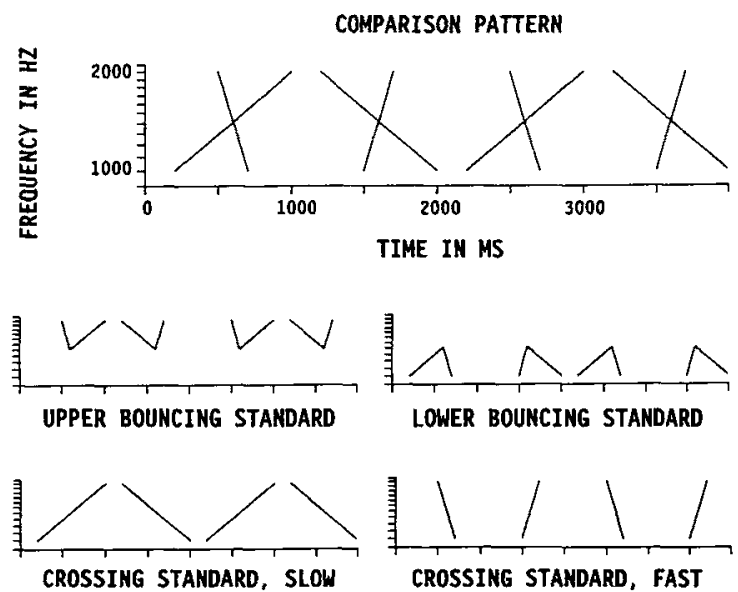

Figure 3. One of the comparison patterns used in Experiment 3 and its four standard patterns. the standard first in the second block, and 6 subjects heard the standard before the comparison in the first block and the comparison first in the second block.

\section{Results}

The bouncing-crossing score was the dependent measure in an ANOVA, with order of blocks as a betweensubjects independent measure and with the following within-subjects independent measures: method (standard first or comparison first), and, for the comparison patterns, rate (fast or slow) of glides in the initially ascending series and rate (fast or slow) of glides in the initially descending series.

The effect of similarity in rate was much more marked in Experiment 3. The interaction of the two rates was highly significant $[F(1,10)=126.07, p<.000001]$. Combining glides with different rates produced negative values of the bouncing-crossing measure, with magnitudes exceeding the positive values when the rates were the same. When the rates differed, the subjects appear to have found it easier to perceive crossing streams than bouncing streams. The mean bouncing-crossing scores appear in Table 3.

One other effect was significant-namely, the four-way interaction of order of blocks, method, and the two rates. This interaction does not readily lend itself to interpretation.

No effect of practice showed up in correlations of the confidence ratings for each of the 32 trials and the trial's place in the order of presentation.

\section{Discussion}

The removal of steady-state tones at the extremes of the frequency range revealed a strong effect of a difference in rate for frequency glides that cross. When the glides differed in rate, the subjects could easily track each glide through the crossing point but they had difficulty perceiving bouncing streams. When the glides had the same rate, crossing was difficult to perceive but the bouncing standards were readily identified as present in the mixture. The salience of bouncing streams in Experiments 1 and 2 , in which glides were joined by steady-state tones, was probably due to the higher average frequency in the upper half of the frequency range and the lower average frequency in the lower half (or to the prolongation of tones at the extremes of frequency); the presence of the steadystate tones may have favored organization on the basis of frequency proximity. The operation of a principle of frequency proximity appears to have largely overwhelmed the effect of rate similarity in those experiments.

The finding that rate similarity had an effect both when the standard was presented before the comparison and when the standard was presented after the comparison suggests that combining glides of different rates facilitates the perception of crossing streams and that combining glides with the same rate most readily produces bouncing streams whether or not subjects are holding a standard pattern in memory. Further research is needed to determine if the perceptual organization of other types of 
Table 3

Mean Differences Between Confidence Ratings for Bouncing Standards and Crossing Standards in Experiment 3

\begin{tabular}{|c|c|c|c|c|c|}
\hline \multirow[b]{2}{*}{ Method } & \multicolumn{2}{|c|}{ Glide Rates } & \multicolumn{3}{|c|}{ Confidence Ratings* } \\
\hline & $\begin{array}{c}\text { Initially } \\
\text { Ascending }\end{array}$ & $\begin{array}{c}\text { Initially } \\
\text { Descending }\end{array}$ & $\begin{array}{c}\text { Mean } \\
\text { Differences }\end{array}$ & Rate(s) & Averages \\
\hline \multirow[t]{2}{*}{ Standard first } & $\begin{array}{l}\text { Slow } \\
\text { Fast }\end{array}$ & $\begin{array}{l}\text { Slow } \\
\text { Fast }\end{array}$ & $\begin{array}{l}5.42 \\
6.92\end{array}$ & Same & 6.17 \\
\hline & $\begin{array}{l}\text { Slow } \\
\text { Fast }\end{array}$ & $\begin{array}{l}\text { Fast } \\
\text { Slow }\end{array}$ & $\begin{array}{l}-6.75 \\
-7.50\end{array}$ & Different & -7.13 \\
\hline \multirow[t]{2}{*}{ Comparison first } & $\begin{array}{l}\text { Slow } \\
\text { Fast }\end{array}$ & $\begin{array}{l}\text { Slow } \\
\text { Fast }\end{array}$ & $\begin{array}{l}4.58 \\
5.00\end{array}$ & Same & 4.79 \\
\hline & $\begin{array}{l}\text { Slow } \\
\text { Fast }\end{array}$ & $\begin{array}{l}\text { Fast } \\
\text { Slow }\end{array}$ & $\begin{array}{l}-8.50 \\
-9.00\end{array}$ & Different & -8.75 \\
\hline
\end{tabular}

*See Data Analysis in General Method section.

stimuli, such as those used in the other experiments reported here, is also independent of the relative order of presentation of the standard and comparison.

When the comparison patterns of Experiment 3 contained glides that differed in rate, the glides also differed in their times of onset and offset and in their duration. To ensure that these differences were not responsible for the results obtained, another experiment was run in which the glides that differed in rate had the same times of onset and offset and the same duration, but they traversed different frequency ranges.

\section{EXPERIMENT 4}

\section{Method}

Stimuli. The comparison patterns were similar to those used in Experiment 3, except that glides could differ in the range traversed but not in duration or time of onset and offset. Because the glides were exponential, forcing them to meet at the midpoint in their duration would have required that the frequency difference between the glides differ at onset and offset. Such differences might affect organization by bringing into play the principle of frequency proximity, so we decided that the glides would have the same frequency difference at onset and offset. The faster glides traveled from 700 to $2700 \mathrm{~Hz}$, or vice versa, and the slower glides traveled between 1450 and $1950 \mathrm{~Hz}$. Glide duration was always $500 \mathrm{msec}$. The faster rate was 3.90 octaves $/ \mathrm{sec}$, and the slower rate was $0.85 \mathrm{octaves} / \mathrm{sec}$; these rates are slightly slower than those of the other experiments. When the two different rates were combined in a comparison pattern, the glides met after 310 or $190 \mathrm{msec}$ at $1616.5 \mathrm{~Hz}$. When glides in both series were fast, the glides crossed after $250 \mathrm{msec}$ at $1374.8 \mathrm{~Hz}$; when the glides in both series were slow, they met after $250 \mathrm{msec}$ at $1681.5 \mathrm{~Hz}$. The different crossing points are close enough in frequency to avoid differences in sensitivity or loudness. Glides were separated at their ends by 500 -msec silent gaps. Each pattern contained four pairs of crossing glides as in Experiment 3, and each took 3,500 msec to play. The rise times and decay times were $20 \mathrm{msec}$. One of the comparison patterns containing glides of different rates is pictured in Figure 4.

The practice stimuli were identical to those used in Experiment 3 with the standard-first method.

\section{Results}

The bouncing-crossing score was the dependent measure in an ANOVA with the following within-subjects independent measures: for the comparison patterns, rate (fast or slow) of glides in the initially ascending series and rate (fast or slow) of glides in the initially descending series.

The main effect of rate was significant for the initially ascending glide series $[F(1,11)=34.52, p<.001]$. Mean scores were higher when the comparison pattern contained an initially ascending series of glides with the fast rate of change.

The interaction of the rates of glides in the two series was significant $[F(1,11)=31.45, p<.001]$, with lower scores when the rates differed. The mean values of the bouncing-crossing measure appear in Table 4 . The absence of large negative differences with glides of different rates (cf. Experiment 3) is due to an elevation of confidence ratings for the bouncing standards (and an elevation of bouncing-crossing scores) whenever one or both of two crossing glides traversed the large $(2000-\mathrm{Hz})$ frequency range; when the glides differed in rate, one of the glides traversed this large range. This elevation of confidence ratings for the bouncing standards is evident in the much higher bouncing-crossing mean for the pattern in which all glides had the fast rate relative to the mean for the pattern containing only glides with the slow rate $(p<$ .05 , in a Tukey $H S D$ post hoc test). The greater extremes of frequency associated with the fast rate may have allowed the subjects to organize the sounds more readily on the basis of frequency proximity when glides with the fast rate were present.

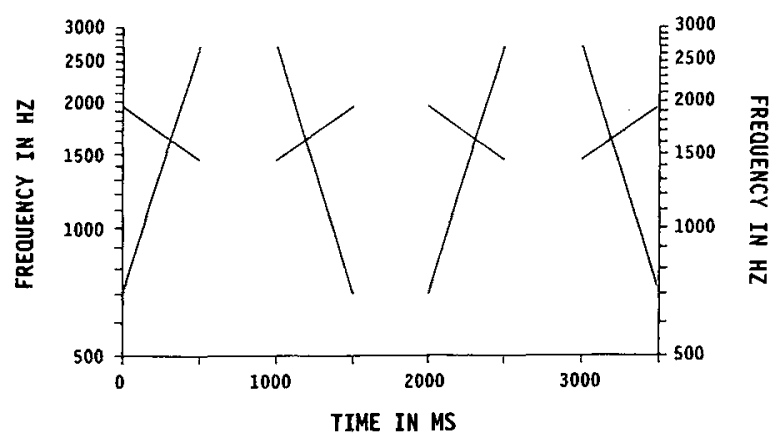

Figure 4. One of the comparison patterns used in Experiment 4. 
Table 4

Mean Differences Between Confidence Ratings for Bouncing Standards and Crossing Standards in Experiment 4

\begin{tabular}{lccccc}
\hline \multicolumn{2}{c}{ Glide } & Rate & & \multicolumn{2}{c}{ Confidence Ratings* } \\
\cline { 1 - 1 } $\begin{array}{c}\text { Initially } \\
\text { Ascending }\end{array}$ & $\begin{array}{c}\text { Initially } \\
\text { Descending }\end{array}$ & $\begin{array}{c}\text { Mean } \\
\text { Differences }\end{array}$ & Rate(s) & Averages \\
${$\cline { 1 - 1 }$} }$ & Slow & 3.58 & Same & 6.38 \\
Fast & Fast & 9.17 & & \\
Slow & Fast & & -1.17 & Different & -0.59 \\
Fast & Slow & 0.00 & & \\
\hline
\end{tabular}

*See Data Analysis in General Method section.

To check for any effect of practice, the confidence ratings for each trial were correlated with the trial's place in the order of presentation. Only 1 (out of 16) correlations was significant $(r=.75, p<.01$, for the trial combining the pattern in which both rates were slow with the bouncing standard that initially ascended). It appears that practice did not generally facilitate the isolation in the comparison mixture of a glide pattern that matched the standard.

\section{Discussion}

In Experiment 4, crossing streams were either easier to perceive than or as easy to perceive as bouncing streams when the rates differed. This finding suggests that the effects observed in Experiment 3 cannot be attributed uniquely to differing times of onset and offset for the glides or to differing durations. The identity of a glide is traced through a crossing point more easily when its rate differs from that of a crossing glide both when the two glides have the same duration but travel through a different frequency range and when the glides have different durations but travel through the same frequency range. The presence of such facilitation of the perception of crossing streams in both experiments, where the only constant was the manipulation of rate of change, suggests that dissimilarity in rate was responsible for the observed results.

When rate covaries with frequency range, the presence, in a mixture, of glides that travel through the large frequency range (glides with the faster rate of change) appears to increase the tendency to organize the sounds according to a principle of frequency proximity, as evident in stronger perceived bouncing. For this reason, the bouncing-crossing measure did not take on large negative values as it did in Experiment 3.

\section{GENERAL DISCUSSION}

The results of four experiments support the hypothesis that frequency glides that differ in rate of change can be tracked through a crossing point more easily than glides that do not so differ. The results fit well with the hypothesis that organizational processes in audition can make use of similarity in rate of change for sounds (or at least for pure tones) changing in frequency. A principle of or- ganization based on similarity in rate of change exists in vision, according to Metzger's (1934) results, and it appears to operate in audition as well.

In the first two experiments, the glides were bounded by steady-state tones at the extremes of the frequency range. The presence of these tones seemed to favor grouping by frequency proximity. As a result, the perception of bouncing streams was common even when the rates of the glides differed. This finding suggests that when a principle of frequency proximity and a principle of rate similarity compete, the principle of frequency proximity dominates. The results of Experiment 4 also support this claim. When one or both of the crossing glides traveled through a large range $(2000 \mathrm{~Hz})$, so that the ends of the glides were separated by a large frequency difference, bouncing was easy to perceive. (If the rates differed, though, crossing was also easy to perceive.) Only in Experiment 3 was bouncing difficult to perceive when the glides differed in rate. In that experiment, the difference in starting and ending frequencies for the glides $(1000 \mathrm{~Hz})$ was half the size of the maximum difference in Experiment 4 , and there were no steady-state tones at the extremes of the frequency range. The effect on streaming of a principle of frequency proximity was accordingly reduced so that rate similarity could more clearly guide organization.

The results of Experiment 3 indicate that learning did not play any major role in determining the perceived streams of sound. The streams experienced by the subjects did not differ radically when the standard pattern (the one to be identified as present or absent) was played after the comparison mixture. This finding suggests that presentation of the standard before the comparison mixture was not essential to obtaining the observed results, at least not with the stimuli used in Experiment 3. The subjects did not need to hear the target pattern, memorize it, and search for it in the mixture in order to hear out that pattern (whenever they did perceive its presence in the mixture). Further evidence that learning and memory played a minimal role is the almost complete absence of any effect of trial; the subjects did not show any improvement across trials in detecting the presence of a pattern matching the standard, except for 1 standardcomparison combination (out of 16) in Experiment 4. These findings suggest that the results reflect the operation of an organizing principle rather than learned schemas for identifying particular auditory patterns.

When an ascending and descending glide with the same rate of change were combined, bouncing (organization by frequency proximity) dominated. A similar effect was observed in earlier studies with series of discrete tones. Tougas and Bregman (1985) observed a dominance of bouncing with binaural presentation of tones that alternated between members of an ascending series and members of a descending series. Deutsch $(1975,1982)$ presented members of a descending and an ascending series of tones simultaneously, with the tones in each of these series alternating between ears (dichotic presentation). 
These stimuli are perceived as a descending series in one ear and an ascending series in the other ear (the "scale illusion"'). Deutsch found that subjects perceived bouncing with these series of tones. The series of tones that initially descended in pitch switched perceptually to an ascending series when the tones in the two series reached a common frequency, and the initially ascending series switched to a descending series. The present study shows that this effect of frequency proximity holds for glides as well as for series of tones when one rate of change is shared by the two glides. (Tougas \& Bregman, 1985, used crossing series of glide segments, but not crossing glides as such.) When the rate of change differs, the streams can cross, sometimes as easily as they can bounce. When factors that favor grouping by frequency proximity (e.g., "pauses" at the extremes of the frequency range, or an extension of the frequency range) are removed (as in Experiment 3 ), the perceived streams bounce only with difficulty; the perception of crossing is much more dominant. It remains to be seen if this effect would obtain with series of discrete tones as well.

Throughout this paper, we have interpreted our results as the effect of a principle of rate similarity (in combination with other organizing principles), but another possibility exists. The strong tendency for the streams to bounce when the rates of the glides match could be due to the operation of a principle of symmetry. When the glides' rates are the same, the bouncing patterns exhibit symmetry around the crossing point. A principle of symmetry (combined with the principle of frequency proximity) would produce bouncing streams. When the rates differ, the bouncing patterns are not symmetric around a reflective axis, so a principle of symmetry might work against the production of bouncing streams. If the top halves (or bottom halves) of two glides (one ascending and one descending in frequency) have different rates, the pattern they would form together would be asymmetric, and the perceptual system may resist such an organization for that reason. (Symmetry within streams is assumed to be what is relevant.) To test for this possibility, stimuli could be constructed in which four glides, two in the upper half of a frequency range and two in the lower half, shared a common point in frequency-time space, but for which each glide had a different rate of change." Symmetry would be lacking for these stimuli, but so would similarity in rate of change for the upper and lower halves of a crossing stream. If streams still tended to cross (at least as easily as they tended to bounce), the effect could be attributed to a principle of symmetry that favors crossing if bouncing implies asymmetric streams. Such a result would provide evidence against the existence of a principle of similarity in rate of change. Research in this direction is planned.

\section{REFERENCES}

Bosinelli, M., Canestrari, R., \& MinguzzI, G. F. (1960). Beitrag zum Problem der gekreuzten und ungekreuzten Bewegungen. Psychologische Beiträge, 5, 8-12.

BREgMAN, A. S. (1990). Auditory scene analysis: The perceptual organization of sound. Cambridge, MA: Bradford/MIT Press.

Bregman, A. S., \& Dannenbring, G. (1973). The effect of continuity on auditory stream segregation. Perception \& Psychophysics, 13, 308-312.

Collins, M. J. (1984). Tone-glide discrimination: Normal and hearingimpaired listeners. Joumal of Speech \& Hearing Research, 27. 403-412.

DeuTsCH, D. (1975). Two-channel listening to musical scales. Journal of the Acoustical Society of America, 57, 1156-1160.

Deutsch, D. (1982). Grouping mechanisms in music. In D. Deutsch (Ed.), The psychology of music (pp. 99-134). New York: Academic Press.

Henke, W. L. (1987). MITSYN languages. Belmont, MA: Author.

KANIZSA, G. (1979). Organization in vision: Essays on gestalt perception. New York: Praeger.

KoffKA, K. (1935). Principles of Gestalt psychology. New York: Harcourt, Brace and World.

Metzger, W. (1934). Beobachtungen über phänomenale Identität. Psychologische Forschung, 19, 1-60.

Porter, R. J., Cullen, J. K., Collins, M. J., \& Jackson, D. F. (1991). Discrimination of formant transition onset frequency: Psychoacoustic cues at short, moderate, and long durations. Journal of the Acoustical Society of America, 90, 1298-1308.

Robinson, D. W. \& DADSON, R. S. (1956). A redetermination of the equal-loudness relations for pure tones. British Journal of Applied Physics, 7, 166-181.

Tougas, Y., \& Bregman, A. S. (1985). Crossing of auditory streams. Journal of Experimental Psychology: Human Perception \& Performance, 11, 788-798.

voN BÉKÉSY, G. (1960). Experiments in hearing. New York: McGraw-Hill.

\section{NOTE}

1. We are grateful to an anonymous reviewer for this valuable suggestion.

(Manuscript received December 4, 1991; revision accepted for publication July 27, 1993.) 